http://jmscr.igmpublication.org/home/

ISSN (e)-2347-176x ISSN (p) 2455-0450

crossref DOI: https://dx.doi.org/10.18535/jmscr/v7i7.54

Journal Of Medical Science And Clinical Research

IGM Publication

An Official Publication of IGM Publication

\title{
To Evaluate the Relationship of HbA1c Levels and Serum Magnesium in Patients with Type II Diabetes and Its Correlation with Diabetic Retinopathy
}

\author{
Authors \\ Vandana Parasar ${ }^{1}$, Nilesh Mohan ${ }^{2 *}$, Rekha Kumari ${ }^{3}$, Bibhuti P Sinha ${ }^{4}$ \\ ${ }^{1}$ Senior Resident RIO, IGIMS, Patna \\ ${ }^{2}$ Additional Professor, RIO, IGIMS, Patna \\ ${ }^{3}$ Additional Professor \& HOD, Deptt.of Biochemistry, IGIMS, Patna \\ ${ }^{4}$ Professor \& HOD, RIO, IGIMS, Patna \\ *Corresponding Author \\ Dr Nilesh Mohan
}

\begin{abstract}
A total of 400 subjects were enrolled for the study: 200 subjects having diabetes mellitus without retinopathy acting as controls, and 200 subjects having diabetes mellitus with retinopathy acting as cases. Basic blood investigation (including FBS, PPBS, serum Mg and HbAlc) were done. Data was collected, correlated and analysed statistically using SPSS version 20. A statistically significant result was observed with the values of serum $\mathrm{Mg} p=0.00001$ and $\mathrm{HbAlc}$ level $p=0.00$ ( $p<0.05)$, which were observed in different grades of diabetic retinopathy. Both fasting and postprandial blood sugars were higher in the subjects with $D R$ as compared to the subjects with no DR. The values were statistically significant for FBS with $p=0.001$ $(p<0.05)$, PPBS $p=0.009$ ( $p<0.05)$ and duration of diabetes mellitus $p=0.0006$ ( $p<0.05)$. Serum magnesium and HbAlc were significantly correlated to severity of DR.

Keywords: diabetic retinopathy, HbAlc, Hypo-magnesemia, type 2 diabetes mellitus.
\end{abstract}

\section{Introduction}

Type 2 diabetes accounts for approximately 90 to $95 \%$ of all diagnosed cases of diabetes. Diabetic patients are prone for multi-system effects of diabetes mellitus such as retinopathy, nephropathy, neuropathy and cardiovascular diseases. Diabetic retinopathy is among the most common ophthalmic complication of diabetes mellitus, being one of the leading causes of blindness among working age people worldwide. $^{1,2}$ WHO has estimated that diabetic retinopathy is responsible for about $4.8 \%$ of the 37 million cases of blindness throughout the world. ${ }^{3}$
Globally, it is estimated that about $30 \%$ people with diabetes mellitus have diabetic retinopathy. ${ }^{4}$ The incidence of blindness is 25 times higher in people with diabetes than in general population. ${ }^{5}$

Due to lack of a reliable and objective method for assessing diabetic control, it has always been the main difficulties to establish a relationship between the degree of hyperglycemia and the long term complication of diabetes. Glycated proteins, primary haemoglobin and serum proteins recording have added a new dimension, as with a single measurement of each of these parameters, we can get a quantitative estimate of the 
glycaemia control over weeks and months. Newer insights into the biochemical changes and molecular events in Diabetic Retinopathy can aid in its presentation and adequate treatment.

Magnesium is the fourth most common cation in the body. Previously underappreciated, this ion is now established as a central electrolyte in a large number of cellular metabolic reactions, including DNA and protein synthesis, neurotransmission, and hormone receptor binding. Accordingly, $\mathrm{Mg}$ depletion has a negative impact on glucose homeostasis and insulin sensitivity in patients with type 2 diabetes, ${ }^{6,7}$ as well as on its complications. Moreover, Hypomagnesemia has been linked to poor glycemic control. ${ }^{8}$

Hypo-magnesemia has been definitely shown to be associated with increased risk of diabetes mellitus, but its association with retinopathy has been inconclusive. Hence this current study has been undertaken to evaluate the association of serum levels of magnesium with retinopathy in type 2 diabetes and correlation with long term control of diabetes mellitus. Newer insights into the biochemical changes and molecular events that occur in diabetic retinopathy can aid in its presentation and adequate treatment.

\section{Methodology}

In the present study, a cross sectional comparative study was done with a sample size of 400 patients with type 2 diabetes, conducted at department of Regional Institute of Ophthalmology (RIO) in collaboration with department of biochemistry, at IGIMS, Patna from April 2017 to November 2018, for prevalence of diabetic retinopathy. Patient's examination was performed as per the proforma meeting the criterias of the study after approval by the hospital ethical review committee. Informed consent was taken from all subjects and details of procedure, involving detailed history taking, complete ocular examination including determination of visual acuity, intraocular pressure, fundus examination done by direct and indirect ophthalmoscopy and Slit lamp biomicroscopy using +90D lens, were explained to them in the local language prior to inclusion into the study. Fundus fluorescein angiography was performed only when clinically necessary. Patients suspected of having CSME were confirmed by doing Fundus Fluorescien Angiography (FFA)/ Optical Coherence Tomography (OCT).

The present study enrolled 400 subjects with type II diabetes: 200 subjects were diabetic without retinopathy acting as control and 200 subjects were diabetic with retinopathy acting as cases.

Based on the ETDRS criteria ${ }^{9}$ patients were graded according to their severity of retinopathy. Fasting blood sample was used to assess HbA1C levels, serum electrolytes including serum magnesium and blood sugar level. HbA1C levels were determined in all patients by the Immunoinhibition technique and serum magnesium was determined by colorimetric method using calmagite dye. In case of patients with asymmetric fundus findings the eye with a more severe grade of diabetic retinopathy was taken into consideration. The cut off values for normal were; HbA1C levels less than 7\%, Serum magnesium level 1.8 to $2.5 \mathrm{mg} / \mathrm{dl}$. The statistical software namely SPSS 20.0 using ANOVA F test, Fischer's exact test were used for the analysis of the data obtained. Differences between groups were evaluated and considered statistically significant at $\mathrm{p}<0.05$.

\section{Results}

In the present study 400 subjects with type II diabetes were enrolled: 200 subjects were diabetic without retinopathy acting as control and 200 subjects were diabetic with retinopathy acting as cases. Out of 200 subjects with retinopathy $141(51.1 \%)$ were male and $59(47.6 \%)$ were female with male to female ratio $\sim 2: 1$. We found that the maximum number of subjects of diabetic retinopathy were from the 50-55 years group, with the mean being 50.86 years, SD: 7.48 years. The mean duration of diabetes for cases was 9.8 years with SD of 5.6 years. 
Mean plasma $\mathrm{Mg}$ concentrations of the cases and the controls were $1.64 \pm 0.38 \mathrm{mg} / \mathrm{dl}$ and $2.38 \pm$ $0.46 \mathrm{mg} / \mathrm{dl}$, respectively $(\mathrm{p}<0.00001)$. Study found $42 \%$ of the cases and $21 \%$ of the control subjects having serum $\mathrm{Mg}$ concentrations below the normal reference range of 1.8 to $2.5 \mathrm{mg} / \mathrm{dl}$. Mean HbA1c concentration in the case subject group was $8.53 \pm 2.43 \%$ in comparison to control group subjects with mean $\mathrm{HbA1c}$ level of $7.50 \pm$ $2.36 \%(\mathrm{p}<0.00)$.

There was a statistically significant result observed with the values of serum Mg p=0.00001 and $\mathrm{HbA1c}$ level $\mathrm{p}=0.00 \quad(\mathrm{p}<0.05)$, which were observed in different grades of diabetic retinopathy. Both fasting and postprandial blood sugars were higher in the subjects with DR as compared to the subjects with no DR. The values were statistically significant for FBS with $p=0.001$ $(\mathrm{p}<0.05)$, PPBS $\mathrm{p}=0.009(\mathrm{p}<0.05)$ and duration of diabetes mellitus $\mathrm{p}=0.0006(\mathrm{p}<0.05)$.

By Fischer exact test, sex and age were not significant predictors of diabetic retinopathy in this sample $(\mathrm{p}>0.05)$.

\section{Charts}

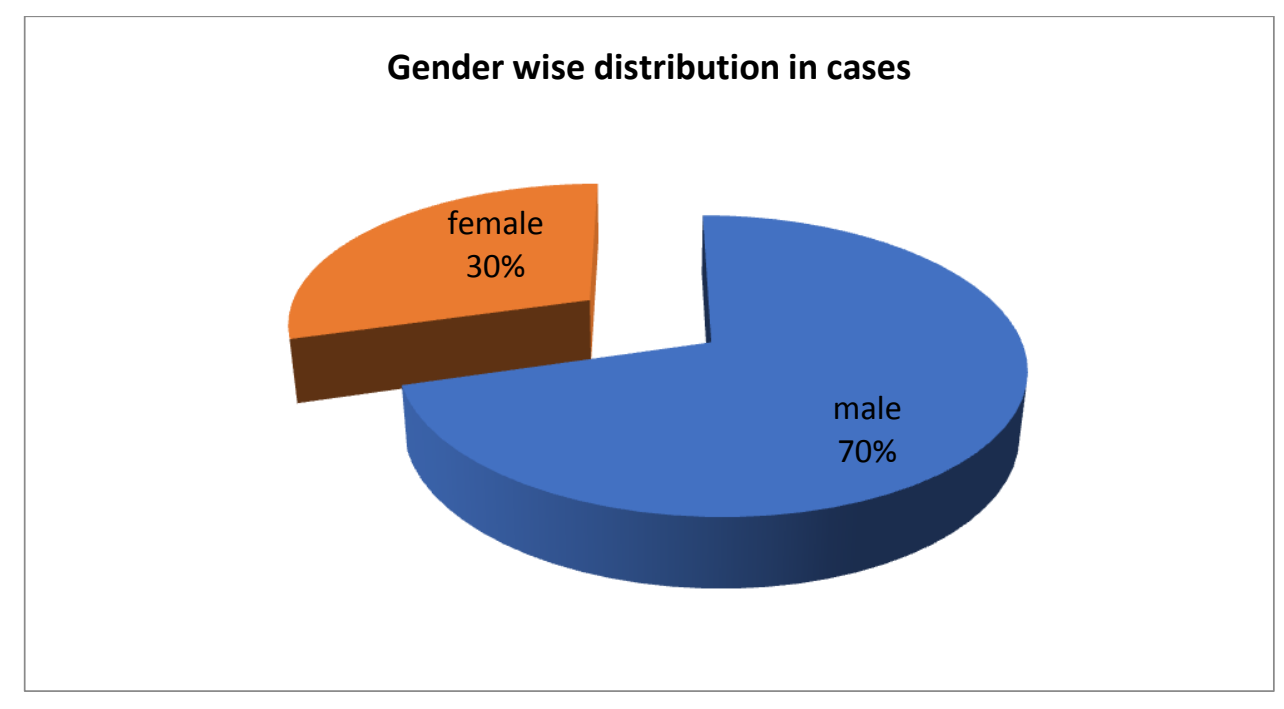

level of HbA1c in cases and control group

a cases control

163

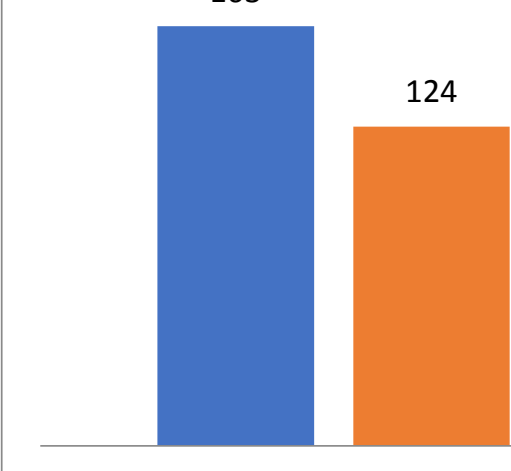

$\operatorname{HbA} 1 \mathrm{c}(>7)$

$\operatorname{HbA} 1 \mathrm{c}(<7)$ 


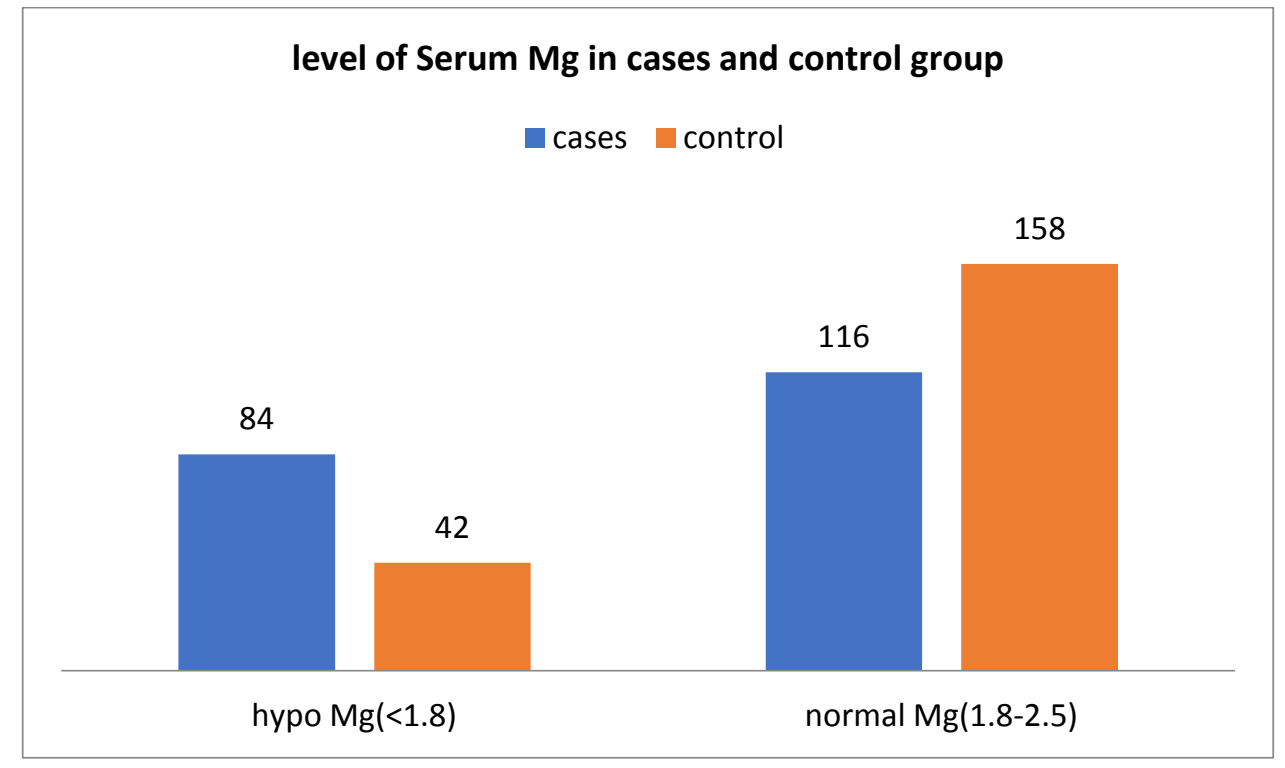

Table

\begin{tabular}{|l|c|c|c|c|c|c|c|c|}
\hline \multirow{2}{*}{} & \multicolumn{4}{|c|}{ Serum Mg } & \multicolumn{4}{c|}{ HbA1c level } \\
\cline { 2 - 9 } & $<1.8 \mathrm{mg} / \mathrm{dl}$ & $\begin{array}{c}1.8- \\
2.5 \mathrm{mg} / \mathrm{dl}\end{array}$ & mean $\pm \mathrm{SD}$ & $\mathrm{p}$-value & $>7 \mathrm{mg} / \mathrm{dl}$ & $\begin{array}{c}<7 \\
\mathrm{mg} / \mathrm{dl}\end{array}$ & $\mathrm{mean} \pm \mathrm{SD}$ & $\mathrm{p}$-value \\
\hline Case & 84 & 116 & $1.64 \pm 0.38$ & 0.00001 & 163 & 37 & $8.53 \pm 2.43$ & 0.00 \\
\hline Control & 42 & 158 & $2.38 \pm 0.46$ & & 124 & 76 & $7.50 \pm 2.36$ & \\
\hline
\end{tabular}

\section{Discussion}

In our study the average serum magnesium levels in patients with diabetic retinopathy were significantly lower than in those with no retinopathy. These observations matches in accordance with Kundu D. et. al. ${ }^{10}$ and Durak R. et. al. ${ }^{11}$, who studied hypomagnesemia as being independently associated with the development and progression of diabetic retinopathy.

The HbA1c levels evaluated glycemic status of the patients evaluated and showed a rise in HbA1C levels with diabetic retinopathy in a statistically significant manner, similar to the studies conducted in previous years. Pirat et. al. conducted a study previously in this regard and inferred that the risk of PDR was six times higher among diabetics with poor glycemic control. ${ }^{12}$ Another similar study, Davis et.al. showed that the HbA1C levels being related to prevalence of retinopathy status in diabetic patients on insulin therapy. ${ }^{13}$ Tight blood glucose control in people with diabetes reduces the rate of progression microvascular complications such as DR, neuropathy and nephropathy. ${ }^{14}$

\section{Conclusion}

A statistically significant correlation was found between increasing level of $\mathrm{HbAlc}$ and hypomagnesemia with severity of diabetic retinopathy.

\section{References}

1. Shaikh MA, Gillani S, Dur-E-Yakta Frequency of diabetic retinopathy in patients after ten years of diagnosis of type 2 diabetes mellitus. J Ayub Med Coll Abbottabad. 2010;22:158-60. [PubMed]

2. Whiting, D. R., Guariguata, L., Weil, C., \& Shaw, J.(2011). IDF diaebetes atlas: global estimates of the prevalence of diabetes for 2011 and 2030. Diabetes research and clinical practice, 94(3),311321.

3. Resnikoff $\mathrm{S}$ et al. Global data on visual impairment in the year 2002. Bulletin of the World Health Organisation, 2004, 82: 844-851.

4. Zheng, Y., He, M., \& Congdon, N., (2012). The worldwide epidemic of 
diabetic retinopathy. Indian journal of ophthalmology, 60(5),428-431.

5. International Diabetes Federation. www.idf.org accessed on $16^{\text {th }}$ October 2011.

6. Durlach J, Rayssiguier Y. Données nouvelles sur les relations entre magnésium et hydrates de carbone. Magnesium 1983;2: 192-224.

7. Nadler JL, Buchanan $T$, Natarajan $R$, Antonipillai I, Bergman R, Rude R. Magnesium deficiency produces insulin resistance and increased thromboxane synthesis. Hypertension 1993;21: 1024-9.

8. Futrakul N, Futrakul P. Renal microvascular and tubular injuries in type II diabetic nephropathy. Kidney Int. 2008;74:390-1. [PubMed]

9. Early Treatment Diabetic Retinopathy Study Research Group. (1991). Early Treatment diabetic Retinopathy Study Design and baseline patient characteristics: ETDRS report number 7. Ophthalmology, 98(5), 741-756.

10. Kundu D, Osta M, Mandal T, Bandyopadhyay U, Ray D, Gautam D. Serum magnesium levels in patients with diabetic retinopathy. J Nat Sci Biol Med. 2013 Jan-Jun; 4(1): 113-116. doi: 10.4103/0976-9668.107270.

11. Durak R, Gülen Y, Kurudirek M, Kaçal M. Determination of trace element levels in human blood serum from patients with type II diabetes using WDXRF technique: A comparative study. J Xray Sci Technol. 2010;18:111-20. [PubMed]

12. Pirat J. Diabetes mellitus and its degenerative complications A prospective study of 4400 patients observed between 1947 and 1963. Diabetes Care 1948; 1: 168-88.
13. Davis RF, Constable IJ, Nicol DJ. Associations of retinopathy and glycosylated haemoglobin in diabetes mellitus. Med J Aust 1980; 2 : 558-60.

14. Khaw Kay-Tee, Wareham N, Luben R, Bingham S, Oakes S, Welch A, Nicholas Day. Glycated haemoglobin, diabetes, and mortality in men inNorfolk cohort of European Prospective Investigation of Cancer and Nutrition (EPIC-Norfolk). BMJ 2003; 6; 322 (7277): 15. 